\title{
SC|A?
}

Eduçaçã̃o, Comunicação e Tecnologia

\section{Jogos virtuais e softwares educacionais para o ensino da matemática nos anos iniciais do ensino fundamental}

\author{
Priscila Rezende Moreira ${ }^{1}$ \\ Evandro Alexandre da Silva Costa ${ }^{2}$
}

\section{Resumo}

Este artigo apresenta potencialidades das mídias digitais para o ensino da matemática nos anos iniciais do ensino fundamental. Para tanto, descrevemos a elaboração e resultados de um minicurso ofertado aos estudantes de Pedagogia, da Universidade do Estado de Minas Gerais, sobre possibilidades do uso de jogos virtuais e softwares que abordam conceitos aritméticos e geométricos aos alunos das primeiras séries da educação básica. Esta pesquisa demonstra que a utilização de mídias digitais nas aulas de matemática nos anos iniciais do ensino fundamental, quando bem planejada, contribui para o desenvolvimento de habilidades algébricas importantes, bem como, no processo de aprendizagem de conceitos dessa ciência para as crianças. Este artigo também aborda a relevância dos estudos acerca das tecnologias educacionais digitais na formação inicial de professores, bem como suas contribuições no planejamento de metodologias de ensino para os anos iniciais do ensino fundamental.

\section{Palavras-chave}

Tecnologia Digital. Ensino de Matemática. Mídia Digital. Softwares Digitais. Jogos Virtuais.

Recebido em: 26/04/2020

Aprovado em: 25/06/2020

\footnotetext{
${ }^{1}$ Doutora em Educação. Professora do Departamento de Métodos e Técnicas de Ensino da Universidade do Estado de Minas Gerais.

e-mail: priscila.moreira@uemg.br

${ }^{2}$ Mestre em Educação Matemática. Professor do Departamento de Métodos e Técnicas de Ensino da Universidade do Estado de Minas Gerais.

Email: evandro.costa@uemg.br
} 


\section{Virtual games and educational softwares for the teaching of mathematics in the early years of fundamental education}

\section{Abstract}

This article presents the potential of digital media for teaching mathematics in the early years of elementary school. To this end, we describe the development and results of a short course offered to students of Pedagogy, from the State University of Minas Gerais, about possibilities of using virtual games and software that address arithmetic and geometric concepts to students in the first grades of basic education. This research demonstrates that the use of digital media in mathematics classes in the early years of elementary school, when well planned, contributes to the development of important algebraic skills, as well as, in the process of learning concepts of this science for children. This article also addresses the relevance of studies on digital educational technologies in the initial training of teachers, as well as their contributions in planning teaching methodologies for the early years of elementary school.

\section{Keywords}

Digital Technology. Mathematics Teaching. Digital Media. Digital Softwares. Virtual Games. 


\section{Introdução}

As mudanças ocasionadas pela tecnologia digital em substituição à tecnologia analógica ocorrem vertiginosamente em todo o mundo e, em praticamente todos os setores da sociedade capitalista: serviços, indústrias, lazer, economia e, também, dentro dos núcleos familiares. Entretanto, percebemos que, especificamente no Brasil, apesar de o avanço da tecnologia digital ser extremamente perceptível, a escola pública ainda se mantém quase intocável aos avanços tecnológicos, permanecendo ainda nos moldes antigos, com pouca inovação nas metodologias de ensino e utilização das tecnologias digitais no processo de ensino-aprendizagem (MOREIRA, 2019). Fato esse que consideramos de grande relevância de estudo, principalmente ao considerarmos a importância da incorporação das mídias digitais na realidade escolar.

De acordo com Borba e Penteado (2005), o uso da informática na educação voltada ao ensino pode propiciar novas representações e situações problemas aos alunos. Para os autores "[...] é fundamental que eles [computadores] também estejam presentes nas atividades escolares" (Idem, p. 87). E continuam, "[...] a alfabetização informática precisa ser considerada como algo tão importante quanto a alfabetização na língua materna e em matemática" (Ibidem).

Ademais, os alunos do ensino fundamental das séries regulares são sujeitos que nasceram inseridos em um contexto digital e são hábeis na utilização das novas tecnologias. De acordo com Oliveira et al. (2016) esses indivíduos são denominados de "nativos digitais". Dessa maneira,

Para compreendermos a geração dos nativos digitais é preciso entender algumas características peculiares desta geração. Palfrey e Gasser (2011) realizaram uma pesquisa global em que identificam as principais características da primeira geração de nativos digitais. Características que advém da utilização das novas tecnologias, rompendo com formas de viver e fazer das gerações passadas (OLIVEIRA, et, al. 2016, p. 2).

Ainda, nesse contexto, é fundamental que políticas e programas educacionais integrem as tecnologias digitais no ensino como campo de investimento e pesquisa, ofertando inclusão digital para os "imigrantes digitais", que nasceram 
antes do advento das mídias digitais, e também, focarem na incorporação (aquisição, infraestrutura, manutenção, formação) dessas mídias, não apenas para sua utilização, mas sim no entendimento desses recursos no contexto e realidade em que vivemos (OLIVEIRA, et al. 2016). Assim:

\begin{abstract}
Ser nativo digital não garante aprender com as tecnologias digitais, mas concede ao aluno possibilidades de aprendizagem por meio delas. Desta forma uma preocupação para gestores e professores está relacionada à utilização das TICs para a aquisição do conhecimento. Portanto, a escola tem um papel fundamental para essas gerações, principalmente em dar sentido a utilização das novas TICs em apoio à aprendizagem. (OLIVEIRA, et al. 2016, p. 11. Grifo Nosso).
\end{abstract}

Entretanto não se trata apenas de equipar as escolas com tecnologias digitais considerando que os alunos farão uso pedagógico desses equipamentos. É necessário ressaltar que esses recursos sozinhos são apenas meios de informação, que dependem de um trabalho didático que as utilizem de maneira satisfatória para o processo de ensino-aprendizagem, com metodologias adequadas. Por isso a necessidade de formação de professores para atuarem com essas mídias (computadores, laptops, smartphones, lousa digital) com intuitos pedagógicos bem definidos na proposta de emenda de suas áreas do conhecimento.

Ademais, de acordo com Serafim e Souza (2011) as ferramentas tecnológicas, recursos e mídias digitais oferecem ao ensino espaços e instrumentos capazes de renovar as situações de interação, expressão, criação, comunicação, informação e colaboração, tornando-o muito diferente daquela maneira tradicionalmente fundamentada nas escolas baseada na escrita e nos meios impressos. Assim, é importante e, atualmente, fundamental o uso dessas ferramentas em prol da educação, principalmente ao considerarmos os problemas existentes nas escolas públicas brasileiras.

Nesse cenário, este artigo apresenta potencialidades do uso das tecnologias digitais voltadas para o ensino da matemática nos anos iniciais do ensino fundamental por meio de jogos virtuais e softwares educacionais, com a utilização de computadores (mídia). Trata-se, também, do relato de experiência 
de um minicurso ofertado aos estudantes do $5^{\circ}$ (quinto) período do curso de pedagogia da Universidade de Estado de Minas Gerais - UEMG, em 2019, sobre as possibilidades que esses recursos digitais podem oferecer no processo de aprendizagem das crianças nas escolas, assim como, a aceitação das novas tecnologias no ensino da matemática no contexto escolar.

Para obtermos os resultados, ao final do minicurso, os estudantes responderam a uma entrevista semiestruturada, que abordava questões relativas às atividades propostas na oficina e, sobre suas experiências com uso das tecnologias digitais no ensino de matemática nas instituições que atuam ou atuaram como estagiários, assim como, suas opiniões acerca da temática deste estudo, apresentadas neste artigo.

\section{Contexto Midiático}

Tarefas como ir ao banco, enviar telegrama pelo correio e fazer ligações no telefone "fixo", estão sendo substituídas por aplicativos nos smartphones ou pelo simples acesso de sites pelo computador. Esse é um processo, de certa maneira, tão rápido, que crianças e até mesmo jovens nunca experimentaram a sensação de ficar mais de 01 (uma) hora esperando serem atendido em um caixa de banco e, tampouco, fazer ligação com ficha utilizando o "orelhão".

Estamos na era da tecnologia da informação e da comunicação (TIC), um momento histórico que é marcado pela substituição da tecnologia analógica para uma tecnologia (digital) muito mais ágil, que ainda produz novos serviços e utilidades aos sujeitos que, de maneira acelerada, com mais rapidez e conforto, obtêm resultados de buscas e informações em apenas alguns segundos (BIANCHETTI, 2008).

As mudanças da tecnologia analógica para a digital ocorrem em todo o mundo, de maneira mais acelerada em alguns países do que em outros, e também, em praticamente todos os setores da sociedade: serviços, indústrias, lazer, economia, nos lares familiares. "No dia-a-dia [...] os meios, os equipamentos, as interfaces, bem como os próprios conteúdos foram ou estão sendo celeremente 
digitalizados" (BIANCHETTI, 2008, p.15). Entretanto, percebemos que, especificamente no Brasil, apesar de o avanço da tecnologia digital ser extremamente perceptível e, já termos modificações das nossas ações no cotidiano altamente perceptíveis pelo uso desses recursos, existe uma instituição que ainda permanece ter pouco incorporado esses avanços: a escola pública.

No contexto da sociedade da informação e comunicação, a escola, que tem também a função de preparar os alunos para o mundo do trabalho (BRASIL, 1998) ainda tem dificuldades em incorporar os computadores no processo de ensino-aprendizagem, mesmo com a indicação do uso dos mesmos "[...] como instrumento de aprendizagem escolar, para que possam estar atualizados em relação às novas tecnologias da informação e se instrumentalizarem para as demandas sociais presentes e futuras" (BRASIL, 1997, p. 67).

Percebe-se que o uso dos computadores nas escolas é algo vislumbrado no Brasil já na década de 1990, a partir das políticas públicas de inserção desses equipamentos. Hoje, diante de tantas mídias digitais (laptops, lousas digitais, smartphones), ainda estamos discutindo a importância da utilização desse primeiro, muitas vezes obsoletos nas escolas públicas brasileiras. Mas destacamos que, o uso dessa mídia digital para o processo de ensino e aprendizagem, com finalidades bem estruturadas, é de extrema importância para o contexto social que os alunos vivenciam em seu cotidiano.

Da mesma maneira, outro conhecimento essencial na vida de todos e, necessário e fundamental para o avanço tecnológico, é a matemática. Esse saber auxilia na compreensão do mundo e contribui para tomadas de decisões em várias situações, das mais variadas naturezas. A matemática pode contribuir na formação cidadã ao proporcionar o desenvolvimento de métodos que enfatizem "[...] a construção de estratégias, a comprovação e justificativa de resultados, a criatividade, a iniciativa pessoal, o trabalho coletivo e a autonomia advinda da confiança na própria capacidade para enfrentar desafios” (BRASIL, 1998, p.27). 
Entretanto, apesar de sua importância em diversos aspectos, o ensino da matemática ainda não é realizado no Brasil de maneira satisfatória. Sendo vista por um grande número de estudantes como uma matéria difícil, temerosa e tida como uma das responsáveis pela reprovação e evasão escolar, sobretudo no ensino médio (STOPASSOLI, 1997).

Assim, ressaltamos a importância de buscar novas metodologias para o ensino da matemática, nas quais, uma das "tendências" apresentadas nos Parâmetros Curriculares Nacionais desde a década de 1990 (PCNs - BRASIL, 1998) é justamente a de utilizar os computadores como ferramenta para a utilização de softwares matemáticos no processo didático. Sabe-se que, apesar dessa mídia ter sido introduzida a mais de $\mathbf{2 0}$ (vinte) anos nas escolas, o computador ainda é uma mídia atual, pois os softwares nele disponíveis são atualizados com frequência, bem como na navegação, os sites e aplicativos de jogos.

\section{O uso da informática no ensino da matemática}

A matemática é considerada, por muitos alunos como uma disciplina maçante e de difícil entendimento, sendo necessárias novas metodologias de ensino que possibilitem um melhor entendimento desta ciência. De acordo com os PCNs (BRASIL, 1998) dentre as diversas tendências metodológicas, destaca-se o uso de tecnologias digitais para o ensino e aprendizagem da matemática. Sobre o uso de computadores em sala de aula, esse documento afirma que:

Eles podem ser usados nas aulas de Matemática com várias finalidades: como fonte de informação, poderoso recurso para alimentar o processo de ensino e aprendizagem; como auxiliar no processo de construção de conhecimento; como meio para desenvolver autonomia pelo uso de softwares que possibilitem pensar, refletir e criar soluções; como ferramenta para realizar determinadas atividades uso de planilhas eletrônicas, processadores de texto, banco de dados etc (BRASIL, 1998, p. 44).

Nessa perspectiva, é interessante afirmar que para o bom uso do computador na sala de aula também é necessário um planejamento bem estruturado que dependa inicialmente de um objetivo claro a se conquistar e da escolha dos recursos e softwares que serão utilizados no processo educativo e, da mesma 
maneira, a perspectiva da necessidade da formação de professores ao longo da sua vida profissional (BRASIL, 1998).

Atualmente, em nossas salas de aula de ensino regular, estamos lidando com alunos que, na sua maioria, estão inseridos em universo tecnológico e sabem manipular essas ferramentas com certa facilidade (CABRAL, 2015). De acordo com esse autor, na era da informação tecnológica “[...] muitos jovens geralmente autodidatas adentram no mundo tecnológico e aprendem inúmeros recursos da internet sendo capazes até de invadir sites oficiais” (CABRAL, 2015, p. 19). Mas, de acordo com Moran (2006), conhecer e manipular as tecnologias não é certeza que esse alunos, ditos nativos digitais, saberão fazer um bom uso desse saber. É necessário tornar esse conhecimento construtivo.

Nessa perspectiva, de acordo com Santos, et al. (2010) utilizar novas tecnologias como alguns softwares matemáticos, pode contribuir para oportunizar a motivação e apropriação do conteúdo estudado em sala de aula. A utilização desses softwares na escola beneficia tanto o professor quanto o aluno, ao promover aulas mais interativas, instigantes e, dessa forma, atrair o interesse do estudante pelo conteúdo muitas vezes dito como difícil no modelo tradicional de ensino.

Assim, percebe-se que os softwares, como os jogos virtuais matemáticos podem ser uma alternativa para trabalhar os conceitos teóricos dos conteúdos matemáticos e para promover uma aula mais dinâmica que incentive o estudo dos conceitos de forma inovadora (MEDEIROS, 2014), além de proporcionar ao aluno criações de estratégias e de resolução de problemas. Portanto, é interessante ressaltar que assim como todo projeto educacional, deve-se traçar um objetivo e realizar um planejamento (BRASIL, 1998). Dessa forma:

O uso de softwares matemáticos não se trata apenas de inserir a tecnologia nas escolas e principalmente nas aulas de matemática, nem fazer uso de novos recursos de modo insignificante como "usar só por usar". Trabalhar com softwares é buscar inovar nas aulas de matemática, de modo que os estudantes por meio desse recurso possam ampliar seus conhecimentos acerca dos conteúdos abordados nos livros, assim como construir novas ideias e produzir conhecimento, sem, necessariamente, estar restrito a 
sala de aula, livro, quadro e ao professor. De modo geral, é vivenciar um novo mundo educacional em que professor e alunos possam estar introssados de maneira significativa, dinâmica, satisfatória e interativa no processo de ensino-aprendizagem (MEDEIROS, 2014, p. 07. Grifo Nosso).

Ademais, percebe-se que a inclusão de recursos tecnológicos, como o uso do computador nas aulas, pode aprimorar o ensino da matemática tornando-a mais dinâmica e atrativa ao aluno (MEDEIROS, 2014). Outro fato interessante é que, com a inserção dessas ferramentas tecnológicas, tais como softwares matemáticos, é possível ter “[...] mudanças nos papéis dos professores e estudantes, evidenciando que ambos rompem com a ideologia do ensino tradicional e abrem-se as novas possibilidades e propostas de se ensinar e aprender matemática com o uso de softwares, jogos online entre outros programas (MEDEIROS, 2014, p. 12).

\section{Minicurso sobre jogos online e softwares matemáticos}

A utilização de jogos no ensino de matemática é uma das tendências metodológicas sugeridas desde os Parâmetros Curriculares Nacionais - PCNs (BRASIL, 1997). De acordo com esse documento, com a utilização de jogos em sala de aula, “[...] as crianças não apenas vivenciam situações que se repetem, mas aprendem a lidar com símbolos e a pensar por analogia (jogos simbólicos): os significados das coisas passam a ser imaginados por elas" (BRASIL, 1997, p. 35). E, também:

Os jogos constituem uma forma interessante de propor problemas, pois permitem que estes sejam apresentados de modo atrativo e favorecem a criatividade na elaboração de estratégias de resolução e busca de soluções. Propiciam a simulação de situações problema que exigem soluções vivas e imediatas, o que estimula o planejamento das ações; possibilitam a construção de uma atitude positiva perante os erros, uma vez que as situações sucedem-se rapidamente e podem ser corrigidas de forma natural, no decorrer da ação, sem deixar marcas negativas (BRASIL, 1998, p. 46). 
Nesse contexto, a utilização de jogos no ensino de matemática pode contribuir para um trabalho de "[...] formação de atitudes, enfrentar desafios, lançar-se à busca de soluções, desenvolvimento da crítica, da intuição, da criação de estratégias e da possibilidade de alterá-las quando o resultado não é satisfatório necessárias para aprendizagem da matemática" (BRASIL, 1998, p. 47). Ainda, de acordo com o Referencial Curricular Nacional para a Educação Infantil (RCNEI), as brincadeiras e o uso de jogos na educação infantil podem propiciar a ampliação dos conhecimentos infantis por meio de atividades lúdicas, além de incentivar a criatividade e se trabalhar com regras (BRASIL, 1998b). Ademais,

No jogo, a resolução de problemas é envolvida pelas própria necessidade de sua execução, onde é necessário elaborar e testar estratégias, levantar hipóteses e refletir sobre as ações do jogador e do seu oponente e, como processo de aprendizagem, que pode ocorrer com a mediação do professor, há também o registro e análise das etapas do jogo (BAUMGARTEL, 2016, p. 7).

O minicurso que nos referimos neste artigo, foi criado com o objetivo de apresentar as possibilidades do uso do computador para o ensino da matemática, especificamente sobre o ensino de frações. Sua realização ocorreu para 22 (vinte e dois) estudantes do $5^{\circ}$ período de Pedagogia, da Universidade do Estado de Minas Gerais. Na oficina do curso foram vistos e trabalhados 10 (dez) jogos online voltados para o ensino da matemática nos anos iniciais do Ensino Fundamental relacionados às frações e, também, o software Paint ${ }^{3}$ na perspectiva do ensino da Geometria e também no ensino de frações.

Além desse software4, foram apresentados aos estudantes (sem proposta de atividade) mais 02 (dois) softwares matemáticos: "Polly"5, que permite

3 O Paint é um editor gráfico simples, que compõe os programas do Windows, e que permite editar imagens em diversos formatos. Uma das atividades que podem ser trabalhadas é o desenho de figuras planas e não planas

4 Destaca-se ainda que, para o minicurso, como a turma estava aprendendo metodologias para o ensino de frações como conteúdo didático do semestre, optou-se por apresentar algumas atividades do Paint que pudessem ser exploradas para esta finalidade.

5 Para baixar esse software basta entrar na página da UFRS (Universidade Federal do Rio Grande do Sul) pelo link: 
planificar os poliedros, permitindo ainda movimentá-los; e o "Super-Logo 3.0"6, uma linguagem de programação para crianças, ideal para desenvolver a lógica, o raciocínio, noção espacial, lateralidade e, interessante para se trabalhar as formas geométricas.

Após a realização das atividades propostas aos estudantes pelos dois professores autores deste artigo, solicitamos que fossem respondidas 04 (quatro) perguntas em uma entrevista semiestruturada, sobre: o minicurso, a importância dos softwares e jogos online, assim como, a relação com esse tipo de conhecimento. A saber:

Pergunta 01: Você concorda que softwares e jogos online podem ser ferramentas pedagógicas úteis no ensino de matemática para os iniciais do ensino fundamental? Justifique.

Pergunta 02: Descreva alguns pontos positivos / e pontos negativos sobre o uso dessas ferramentas no ensino da matemática para os anos iniciais do ensino fundamental.

Pergunta o3: Você trabalha ou realiza estagio em algum colégio atualmente? Caso resposta afirmativa: a escola que trabalha ou realiza estágio é particular ou pública? A escola em que trabalha ou realiza estágio utiliza esse tipo de ferramenta no ensino e aprendizagem nos anos iniciais do Ensino Fundamental?

A pergunta 04 foi destinada apenas àqueles alunos que responderam que a escola em que trabalham ou estagiam não utilizam esse tipo de recurso digital.

http://www.edumatec.mat.ufrgs.br/softwares/soft_geometria.php. Nesse link, encontra-se ainda vários outros softwares como: o Geogebra e a Cinderela que são softwares que possibilitam um trabalho com a geometria.

${ }^{6}$ Uma das atividades que os alunos podem desenvolver no Super-Logo é o de criar retângulos, triângulos e quadrados. Sendo assim, basta que eles utilizem o raciocínio lógico e os comandos PF (para frente), PE (Para a esquerda) e PD (Para direita). 
Pergunta 04: Caso sua reposta tenha sido negativa quanto ao uso dessas tecnologias, explique o motivo, em sua opinião, do motivo dessa escola não utilizar esses recursos digitais.

Sobre a primeira pergunta $100 \%$ dos alunos, no total de 22 , responderam que concordam que softwares e jogos online podem ser ferramentas pedagógicas úteis no ensino de matemática para os iniciais do ensino fundamental. Entre as respostas dadas como justificativa apresenta-se a resposta do aluno o5 que relata que "[...] é uma forma de trabalhar com os conteúdos passados em sala, de uma forma mais lúdica, aproximando a vivência tecnológica do aluno a outras formas de aprendizado".

O aluno 07, apesar de concordar que os jogos online e os softwares podem ser ferramentas úteis para o ensino da matemática, afirma ainda que: "Acha válido e que pode ser bem proveitoso, porém os jogos precisam ser bem pensados em todos os aspectos para que sejam claros autoexplicativos e que tenham folgas entre as atividades e que sejam aplicados esporadicamente".

Sobre os pontos positivos verificou-se que $32 \%$ afirmou que os alunos aprenderiam brincando, ou seja, de forma lúdica; 45\% alega que essa metodologia traria mais motivação atraindo os alunos para o aprendizado da matemática e, 23\% que o uso dessas ferramentas auxiliaria no aprendizado do conteúdo e também no desenvolvimento do raciocínio lógico.

A respeito dos pontos negativos verificou-se que 50\% dos alunos pesquisados acredita que o uso de computadores ligados à Internet contribuiria para a dispersão da atenção dos discentes, 10\% respondeu que um dos pontos negativos são os problemas da falta de materiais e recursos adequados no interior da escola. O restante da turma (40\%) respondeu que não percebe nenhum ponto negativo.

o9 (nove) alunos afirmaram que já trabalham em escolas: 03 (três) em escolas públicas e 06 (seis) na rede particular de ensino. Quanto ao uso dos jogos online para o ensino da matemática, apenas 03 (três) deles afirmaram que a escola 
utiliza esses recursos nas escolas particulares que atuam. E nenhum nas escolas públicas.

Como justificativa pelo fato de a escola que trabalham não utilizar os jogos online para o ensino da matemática, os alunos deram as seguintes respostas:

Aluno 02 - "A escola acredita que os jogos antigos funcionam bem, assim como as barras de Cusenaire, os blocos lógicos e o material dourado. Por isso não utilizariam esse tipo de ferramenta”.

Aluno 11 - "A instituição ainda não utiliza tais ferramentas, pois, trabalha com os anos iniciais da Educação Infantil e não gostariam de trabalhar com computadores para essa idade”.

Aluno 12 - "Não tem computadores na escola para os alunos da Educação Infantil e anos Iniciais do Ensino Fundamental”.

Aluno 14 - "A escola que trabalho é uma UMEI e não tem computadores para os alunos".

Aluno 17 - "Não tem computadores na escola e nem laboratório de informática na escola em que trabalho. Além disso, o professor de lá não saberia mexer”.

Aluno 21 - "A escola é muito tradicional e não trabalharia com computadores para essa faixa etária. Os professores que trabalham aqui, nem sabem ligar o computador".

Diante das respostas à pergunta 04, é importante reforçar a necessidade dos professores participarem e realizarem cursos de formação continuada e que esses profissionais sejam possibilitados a aprender a utilizar as tecnologias digitais de maneira pedagógica. É possível perceber que os alunos do curso de Pedagogia que realizaram a oficina, apesar de acharem interessante, dinâmico e motivador o uso dos computadores para o ensino da matemática, relataram as dificuldades de utilizarem os recursos digitais. 
Nesse sentido, Moran (1999) assinala que ensinar com as novas mídias somente será inovador se for acompanhado de mudanças nos paradigmas escolares que estão atreladas às políticas e interesses públicos. A necessidade de mostrar as utilidades das mídias para além da diversão e do entretenimento é mais um dos papeis dos professores, elas não podem vir desassociadas de uma percepção crítica sobre suas funcionalidades. Isso se refere a qualquer mídia, e não somente a digital. Mas essa é, na atualidade, a mais requerida por esses alunos nas suas realidades cotidianas.

É interessante destacar que Borba e Penteado (2005) afirmam que algumas pessoas asseguram que o uso da máquina pode fazer com que as crianças se tornem apenas repetidores de tarefas, "apertando" teclas, e dependentes sempre da "máquina". Os autores também revelam em sua pesquisa que muitos professores temem serem substituídos pelos computadores. Como se o uso do computador fosse algo a ser combatido e não agregado no ambiente escolar.

Borba e Penteado (2005) mostram, também, que alguns professores afirmam não utilizar informática nas aulas por não terem boas condições de trabalho profissional: "Como comprar computadores para as escolas, se nem mesmo há giz em várias delas? Como pensar em computadores na escola, se os professores continuam sendo mal remunerados?” (BORBA e PENTEADO, 2005, p. 13).

Reforçamos que, o pensamento de incorporação das tecnologias digitais nas escolas vai ao encontro do que é sugerido nos PCNs (BRASIL, 1998, p. 140) que indica que: "a tecnologia deve servir para enriquecer o ambiente educacional, propiciando a construção de conhecimentos por meio de uma atuação ativa, crítica e criativa por parte de alunos e professores”. Ainda, que o computador "[...] pode ser usado como elemento de apoio para o ensino (banco de dados, elementos visuais), mas também como fonte de aprendizagem e como ferramenta para o desenvolvimento de habilidades (BRASIL, 1997, p. 35)”. Dessa maneira, a informática na educação veio para acrescentar e fomentar o uso de novas metodologias de ensino e não para substituir os professores em sala de aula. 


\section{Considerações finais}

Em pleno século XXI as TICs estão inseridas em nossa rotina de vida, em diversos âmbitos da sociedade onde já são percebidas com naturalidade. Nesse sentido, os recursos educativos digitais, podem potencializar de forma pedagógica as aulas de matemática, principalmente ao considerarmos que essa disciplina é percebida por muitos alunos como de difícil abstração. Dessa forma podemos dizer que, os softwares e jogos virtuais, devido a sua ludicidade, podem motivar o aprendizado do aluno e envolvê-lo de forma ativa, além de propiciar o desenvolvimento da autoconfiança, da socialização, e do desenvolvimento do raciocínio lógico (BAUMGARTEL, 2016). Nessa perspectiva, pode-se relatar ainda, que os jogos podem contribuir para que o aluno trabalhe resoluções de problemas matemáticos, pois o mesmo deverá buscar estratégias para o desenvolvimento dos jogos.

Por todos os motivos elencados nesse artigo, consideramos que a utilização de jogos virtuais e softwares nas aulas de matemática, quando bem planejado, pode ser uma metodologia capaz de contribuir para desenvolver habilidades como criação de estratégias e resolução de problemas, bem como, auxiliar no processo de aprendizagem de conceitos matemáticos.

Mais recente, em âmbito nacional, o Ministério da Educação (MEC), lançou em 2014, o projeto "Pacto Nacional pela Alfabetização na Idade Certa" (BRASIL, 2014), que contém, entre outros cadernos, o intitulado: "Materiais virtuais para o ensino da Geometria”, apresentando softwares e jogos voltados para o ensino da geometria, que vai ao encontro do uso dos computadores, possibilitando às crianças em idade escolar possibilidades de acesso às diversas fontes de informações, ludicidade e também de conhecimento.

Nessa perspectiva, destacamos a existência de softwares e jogos virtuais que tratam do ensino da matemática nos anos iniciais do ensino fundamental desenvolvendo habilidades matemáticas, raciocínio lógico, tabuada, e na elaboração de conceitos matemáticos como: frações e geometria plana que 
podem ser utilizados nas séries iniciais do ensino fundamental, tais como as trabalhadas no minicurso, objeto deste artigo.

No ponto de vista do uso dessas tecnologias pelos professores, Sancho (2009) afirma que somente os professores que se arriscam a ir além do que lhes foi ensinado e das suas próprias convicções de ensino tradicional, desenvolvendo a capacidade de aprender enquanto ensinam, serão capazes de abordar as questões presentes e futuras da educação. No entanto, assim como a autora, acreditamos que os professores sozinhos com suas boas intenções não conseguem suprir as necessidades reais da incorporação das mídias digitais nas escolas, principalmente ao considerarmos que o excesso de trabalho gera uma condição de trabalho precária, que muitas vezes impede esses docentes de realizarem cursos por "conta própria".

\section{Referências}

BAUMGARTEL, Priscila; O uso de jogos como metodologia de ensino da Matemática In: XX Ebrapem - Encontro Brasileiro de Estudantes de PósGraduação em Educação Matemática. Curitiba - Paraná; 2016.

BIANCHETTI, Lucídio. Da chave de fenda ao laptop: Tecnologia Digital e novas qualificações: desafios à educação. 2. ed. Florianópolis: Editora da UFSC, 2008. $250 \mathrm{p}$.

BORBA, Marcelo Carvalho; PENTEADO, Miriam Godoy. Informática $e$ Educação Matemática. 3 ed. Belo Horizonte: Autêntica, 2005.

BRASIL. Secretaria de Educação Fundamental. Parâmetros Curriculares Nacionais - Primeiro e Segundo Ciclos do Ensino Fundamental: Matemática. Brasília, DF: MEC/SEF, 1997.

BRASIL. Secretaria de Educação Fundamental. Parâmetros Curriculares Nacionais - Terceiro e Quarto Ciclos do Ensino Fundamental: Matemática. Brasília, DF: MEC/SEF, 1998.

BRASIL. Ministério da Educação e do Desporto. Secretaria de Educação Fundamental. Referencial Curricular Nacional para a Educação Infantil. Ministério da Educação e do Desporto, Secretaria de Educação Fundamental. Brasília: MEC/SEF, 1998b.

BRASIL. Pacto Nacional pela Alfabetização na Idade Certa: Geometria. Ministério da Educação, Secretaria de Educação Básica, Diretoria de Apoio à Gestão Educacional. -Brasília: MEC, SEB, 2014. 96 p. 
CABRAL, Ronaldo Vieira. O ensino de matemática e a informática: uso do Scratch como ferramenta para o ensino e aprendizagem da geometria. 2015. Dissertação (Mestrado em Ciências da Educação e Multidisciplinaridade) Faculdade do Norte do Paraná, Sarandi, 2015.

MARCONI, Marina de Andrade; LAKATOS, Eva Maria. Fundamentos de Metodologia Científica. 6 ed. São Paulo: Atlas, 2010. 315 p.

MEDEIROS, Rosimere Pereira. Softwares matemáticos: O uso de novos recursos tecnológicos para o processo de ensino e aprendizagem da matemática. REBES - Revista Brasileira de Educação e Saúde, Pombal, v. 4, n. 3, p. 6-12, $\mathrm{jul} / \mathrm{set} .2014$.

MORAN, José Manuel. Mediação pedagógica e o uso da tecnologia. In: Novas tecnologias e mediação pedagógica. MORAN, José Manuel, MASETTO, Marcos, BEHRENS, Marilda. $12^{\mathrm{a}}$ ed. São Paulo: Papirus, 2006.

MORAN, José Manuel. O Uso das Novas Tecnologias da Informação e da Comunicação na EAD - uma leitura crítica dos meios. Palestra. 8p. Palestra proferida no evento "Programa TV Escola - Capacitação de Gerentes". Belo Horizonte e Fortaleza. 1999. Disponível em: $<$ http://portal.mec.gov.br/seed/arquivos/pdf/T6\%2oTextoMoran.pdf>. Acesso em 26 de abril de 2020.

MOREIRA, Priscila Rezende. Mídias Digitais no Ensino Médio Estadual de Minas Gerais. 2019. Tese (Doutorado em Educação) - Faculdade de Educação, Universidade Federal de Minas Gerais, Belo Horizonte, 2020.

OLIVEIRA, Pablo Roberto Fernandes; FILHO, Sérgio Morais Cavalcante; MEDEIROS; Rosângela de Araújo; In: INCLUSÃO DIGITAL: o papel da escola no contexto da cibercultura; II Congresso Internacional de Educação Inclusiva; Campina Grande, 2016.

SANCHO, Juana María. Qué educación, qué escuela para el futuro próximo? Educatio Siglo XXI, Vol. 27, 2009, pp. 13-32.

SANTOS, Rosana; LORETO, Aline Brum; GONÇALVES, Juliano Lucas. Avaliação de softwares matemáticos quanto a sua funcionalidade e tipo de licença para uso em sala de aula. In: Revista de ensino de Ciências e Matemática, REnCiMa, v. 1, n. 1, p. 47-65, 2010.

SERAFIM, Maria Lúcia; SOUZA, Robson Pequeno; Multimídia na educação: o vídeo digital integrado ao contexto escolar. In: SOUSA, Robson Pequeno de; MIOTA, Filomena da M., CARVALHO, Ana Beatriz Gomes (Org.) Tecnologias digitais na educação [online]. Campina Grande: EDUEPB, 2011. 276 p.

STOPASSOLI, Márcia Aurélia. Reflexões Matemáticas. Blumenau: Editora da FURB, 1997. 